\title{
Assessment of local genetic structure and connectivity of the common eelgrass Zostera marina for seagrass restoration in northern Europe
}

\author{
Lourdes Martínez-García ${ }^{1,3}{ }^{\text {, Bengt Hansson }}{ }^{1}$, Johan Hollander ${ }^{2, *}$ \\ ${ }^{1}$ Department of Biology, Lund University, 22362 Lund, Sweden \\ ${ }^{2}$ World Maritime University, Sasakawa Global Ocean Institute, 21118 Malmö, Sweden \\ ${ }^{3}$ Present address: Centre for Ecological and Evolutionary Synthesis (CEES), Department of Biosciences, University of Oslo, \\ Blindernveien 31, NO-0371 Oslo, Norway
}

\begin{abstract}
Seagrass meadows are one of the most important habitats in coastal regions since they constitute a multifunctional ecosystem providing high productivity and biodiversity. They play a key role in carbon sequestration capacity, mitigation against coastal erosion and as nursery grounds for many marine fish and invertebrates. However, despite these ecosystem functions and services, seagrass meadows are a threatened ecosystem worldwide. In the Baltic Sea, seagrass meadows have declined rapidly, mainly because of eutrophication, anthropogenic activities and climate change. This decline has the potential to erode the genetic variation and genetic structure of the species. In this study, we assessed how genetic variation and genetic differentiation vary among Zostera marina meadows and with a number of environmental characteristics in the county of Scania in southern Sweden. A total of 205 individuals sampled at 12 locations were analysed with 10 polymorphic microsatellite loci. Results showed that in spite of anthropogenic impacts and climate change pressures, locations of $Z$. marina possessed high genetic variation and weak genetic differentiation, with 3 major genetic clusters. Long-distance dispersal and/or stepping-stone dispersal was found among locations, with higher migration rates within the west coast. Organic matter, salinity and maximum depth appeared to be factors most strongly associated with the genetic structure and morphological variation of $Z$. marina. These findings contribute significantly in the identification of potential donor sites and the viability of impacted areas to recover from natural recruitment, for the development of effective transplantation measures of $Z$. marina in the southern Baltic Sea and temperate regions elsewhere.
\end{abstract}

KEY WORDS: Zostera marina - Genetic structure · Genetic variation · Environmental variables · Restoration · Transplantation

\section{INTRODUCTION}

Global climate change and increasing rates of coastal urbanization and fisheries are promoting the loss of our coastal ecosystems (Waycott et al. 2009, Boström et al. 2014). For instance, seagrass meadows are biotopes providing a large number of key functions (Rönnbäck et al. 2007) such as absorption of nutrients, carbon sequestration, primary and secondary productivity, provisioning of nursing

${ }^{*}$ Corresponding author: johan.hollander@wmu.se and foraging areas for species with large economic importance and modification of substrate that increases the biological diversity in the ecosystem (Boström et al. 2014). Nonetheless, their global distribution has decreased by nearly $29 \%$ over the last 150 yr (Waycott et al. 2009). In Europe, this loss may have peaked during the 1970s and 1980s, where the Baltic Sea has experienced, by far, the largest percentage of losses of seagrass area (67\%), followed by a $36 \%$ loss in the Atlantic Ocean and a

(C) The authors 2021. Open Access under Creative Commons by Attribution Licence. Use, distribution and reproduction are unrestricted. Authors and original publication must be credited. 
$21 \%$ loss in the Mediterranean Sea (de los Santos et al. 2019).

As a result of these losses, adverse damages at shorelines - caused by elevated sea levels, intense rainfall and extreme weather events - combined with the slow rate of recovery of seagrasses meadows requires human intervention through different actions such as restoration (Jackson et al. 2021). Optimal restoration of seagrass meadows is dependent on habitat quality and environmental characteristics as well as the genetic potential of the seagrass populations, as this factor has a conclusive influence on conservation success (Ferber et al. 2008). Furthermore, an understanding of the connectivity of populations can provide significant information about the species' biology and evolutionary dynamics in terms of gene flow, recolonization, adaptation and, ultimately, species resilience (e.g. Kendrick et al. 2017). Therefore, genetic diversity, clonal diversity $(R)$, genetic structure and connectivity within and between populations are all important for species persistence (Ferber et al. 2008, Connolly et al. 2018).

In Zostera marina (also known as common eelgrass), several studies have recently shown the possibility of long-distance dispersal (Jahnke et al. 2018, 2020), and although the negatively buoyant seeds are usually only dispersed over a few meters, rafting shoots with viable seeds can travel up to $150 \mathrm{~km}$ (Källström et al. 2008). Still, the geography and composition of the coast is relevant for the length of dispersal, since e.g. an archipelago compared to a simple coastline offers different dispersal prerequisites for rafting seeds (Källström et al. 2008). Hence, ecological, geographical and genetic processes must be considered together to provide management actions for successful restoration projects, to understand the connectivity and isolation for demographic status and better predict threats from changing climate conditions (Procaccini et al. 2007, Eriander et al. 2016). In the Baltic Sea, populations of $Z$. marina are rapidly declining (Schmidt et al. 2012, de los Santos et al. 2019). Its distribution in southern Sweden has experienced a severe loss since 2004 (Länsstyrelsen Skåne 2016), and about $60 \%$ of its coverage has been lost in adjacent Skagerrak (Boström et al. 2014, Jahnke et al. 2018). Of particular interest is the shift in environmental conditions in this area: a continuous salinity gradient from the northern Skagerrak, with a characteristic marine environment via the Baltic Sea, and finally Bothnian Bay, which is almost a freshwater habitat (Rönnbäck et al. 2007). This salinity gradient constitutes different physical and biological conditions that promote changes in com- munity composition that may influence the genetic diversity and species strategies for local adaptation (Rönnbäck et al. 2007, Procaccini et al. 2007). Still, we know very little about the genetic structure of $Z$. marina in southern Sweden. This information is vital for successful seagrass restoration (Infantes et al. 2016, Moksnes et al. 2018) since data concerning the genetic structure and gene flow is significant for identifying suitable donor populations (Boström et al. 2014). For that reason, we examined the population genetic variation and structure of $Z$. marina over a local scale in the county of Scania in southern Sweden, according to a number of different environmental factors and geographical distances.

\section{MATERIALS AND METHODS}

\subsection{Study system and study sites}

Zostera marina is a subtropical and temperate seagrass distributed in the Northern Hemisphere (Olsen et al. 2004, Campanella et al. 2010b). In southern Sweden, it inhabits stony and soft bottom (sandy and muddy sediments) habitats of low to moderate wave exposure from 2 to $9 \mathrm{~m}$ depth (Länsstyrelsen Skåne 2016), across a salinity gradient between 2 and 20 psu (Länsstyrelsen Skåne 2016). Reproduction can be sexual (seed production and hydrophilous pollination) or vegetative (rhizomes and shoots; Reusch et al. 2000). Overall, restricted dispersal ( 2 to $15 \mathrm{~m}$ ) via negatively buoyant seeds has been found for $Z$. marina (Reusch et al. 1999); yet dispersal rates via floating fruit shoots within the Baltic Sea have been reported to be longer, up to $54 \mathrm{~km}$ (Reusch 2002), and as much as $150 \mathrm{~km}$ elsewhere (Källström et al. 2008). In the county of Scania in southern Sweden, the season for flowering shoots varies according to sea temperatures, but usually takes place in June with a biomass peak in August to September (Länsstyrelsen Skåne 2016). Z. marina meadows along the east coast of southern Sweden are generally smaller than those on the west coast, which is related to greater exposure and stronger currents, together with a lack of suitable substrate (Länsstyrelsen Skåne 2016).

\subsection{Sampling design}

Individual shoots of $Z$. marina were sampled at 12 locations around the coasts of Scania in southern Sweden in June 2018 (Fig. 1, Table 1). The geographical area where sampling was conducted varied in 
size depending on the extension of the meadow. Between 7 and 24 individual shoots of $Z$. marina were collected at each location with a minimum distance of $5 \mathrm{~m}$ apart (Campanella et al. 2010a) to minimise sampling the same clone (Procaccini et al. 2007). At each site (except Skillinge [SKI] and Helsingborg [HEL]; see Fig. 1), samples were collected along 5 transects perpendicular to the shore, with a distance between transects of 4 to $5 \mathrm{~m}$ and at a depth of 30 to $200 \mathrm{~cm}$ depending on the location of the meadow (see Table 1). If no shoot was present at the next position in the transect, it was collected from the closest position available within the transect. There were only 2 exceptions to this sampling strategy. First, at SKI, where the small size of the meadow prevented a collection of shoots every $5 \mathrm{~m}$, shoots were collected every $1 \mathrm{~m}$ along 4 transects with a distance between them of 1 to $1.5 \mathrm{~m}$. Second, at HEL, where depth prevented a larger collection, samples were collected every $5 \mathrm{~m}$ apart in a straight line perpendicular to the shore at $190 \mathrm{~cm}$ depth. Specific geographic coordinates for each shoot were obtained with GPS. Shoots were collected manually with snorkelling equipment. Fresh tissue from the plants was dried and stored using silica gel until DNA extraction.

Additionally, data for 7 environmental factors (organic matter, salinity, temperature, minimum and maximum depths, sediment, exposure) and 2 morphological variables (leaf length and leaf width) known to influence the distribution and fitness of seagrasses

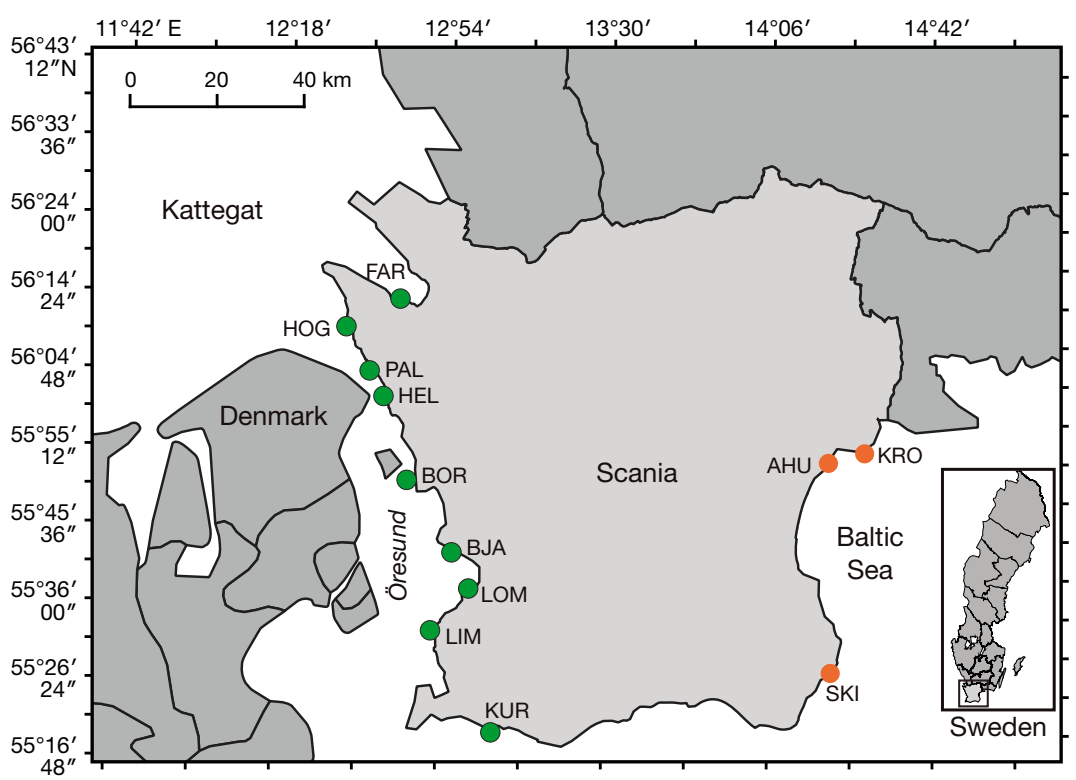

Fig. 1. Sampling locations for Zostera marina in Scania, southern Sweden (Table 1). Green dots: locations on the west coast; orange dots: locations on the east coast. FAR: Farhult; HOG: Höganäs; PAL: Pålsjö; HEL: Helsingborg; BOR: Borstahusen; BJA: Bjärred; LOM: Lomma; LIM: Limhamn; KUR: Kurland; SKI: Skillinge; AHU: Åhus; KRO: Krogstorp were considered for each location (Krause-Jensen et al. 2011). Meadow morphology (continuous or patchy), temperature (mean summer temperature in the area), and sediment (sand, shells, and/or pebbles) were obtained from SeagrassSpotter (https://seagrassspotter .org), the Swedish Meteorological and Hydrological Institute (www.smhi.se), and the Försvarets Center för Operativ Oceanografi (https://fcoo.dk). Data for wave exposure (exposed, sheltered or semi-sheltered) were obtained from personal observations in the field. Leaf length and leaf width of every leaf collected (5 to 7 leaves) from each individual were measured before samples were stored in silica gel. Moreover, to determine salinity and organic matter values within the meadows, water samples and substrate samples (from $10 \mathrm{~cm}$ depth) were taken in situ at each location (Table 1).

\subsection{DNA extraction and microsatellite amplification}

Genomic DNA was extracted from leaf tissue according to the quick-start protocol from Qiagen DNeasy Plant Mini kit (QIAGEN), with slight modifications. Incubation with buffer AP1 and RNAse was $60 \mathrm{~min}$ at $65^{\circ} \mathrm{C}$. Then, $130 \mu \mathrm{l}$ of P3 buffer was added and incubated on ice for $45 \mathrm{~min}$. DNA samples were genotyped using 10 fluorescence-labelled microsatellite loci described by Reusch et al. (1999) and Reusch (2000) (Table S1 in Supplement 1 at www.int-res.com/articles/ suppl/m664p103_supp1.pdf). The DNA extract was amplified according to standard protocols previously reported (Reusch et al. 1999, Reusch 2000) and in multiplex mixtures with $2 \mu \mathrm{l}$ of genomic DNA, $5 \mu$ of the Qiagen reaction mix, and $0.2 \mu \mathrm{l}$ of forward and reverse primers brought up to a total volume of $10 \mu \mathrm{l}$ with deionized water. PCR products were separated on an ABI 3500 capillary sequencer and scored with GeneMarker v.2.6.3 software (SoftGenetics).

\subsection{Data analysis}

\subsubsection{Clonal and genetic diversity}

Duplicate multilocus genotypes (MLGs) were identified with the for- 


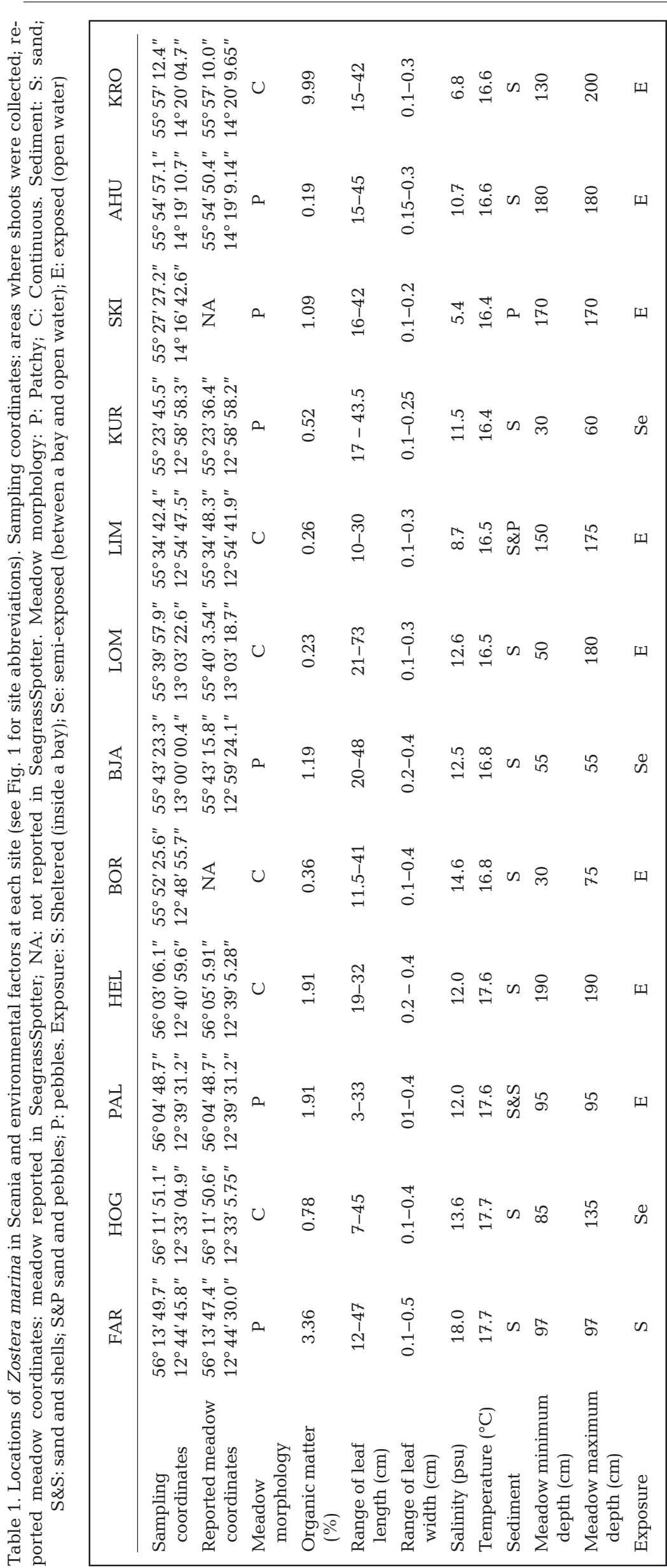

mula MLG-1/N1 (Dorken \& Eckert 2001) and removed with 'RClone' (Bailleul et al. 2016) in R v.3.5.1 (R Core Team 2018). Only one MLG for each clone was included for further analyses. Each microsatellite locus was assessed for the presence of null alleles using 'MicroDrop' (Wang \& Rosenberg 2012) with 10000 permutations at a $95 \%$ confidence level and 100 replicates. Deviations from Hardy-Weinberg equilibrium (HWE) and linkage equilibrium (i.e. presence of linkage disequilibrium, LD) at each location and among all pairs of loci were tested using GENEPOP on the Web v.4.2 (100 batches and 1000 iterations per batch; Rousset 2008) and 'FSTAT' v.2.9.3.2 (Goudet 2002), respectively. Results for exact tests for both HWE and LD were adjusted using Bonferroni corrections. To determine the statistical power of the 10 microsatellite loci to detect population structure among locations of $Z$. marina, power simulations were calculated with 'POWSIM' (Ryman \& Palm 2006), using allele frequencies of each location considering their corresponding MLGs. Statistical probability was assessed under Fisher's exact p-value method, with an effective population size $\left(N_{\mathrm{e}}\right)$ of 2000, with 1000 replicates, generations to drift before sampling $(t)$ of 0,10 and 100 and 100000 interactions. To analyse genetic variation, observed heterozygosity $\left(H_{0}\right)$, expected heterozygosity $\left(H_{\mathrm{e}}\right)$, and inbreeding coefficient $\left(F_{\mathrm{IS}}\right)$ were calculated with Arlequin v.3.5.2.2 (Excoffier \& Lischer 2010). Allelic richness $\left(A_{R}\right)$ standardized to the lowest number of MLGs (MLG $=7$ ) was calculated with 'FSTAT'. The total number of alleles $\left(N_{A}\right)$ and private alleles $\left(P_{A}\right)$ were tested in GenAIEx v.6.5 (Peakall \& Smouse 2012). $N_{\mathrm{e}}$ was calculated using a LD method in NeEstimATOR v.2 (Do et al. 2014). $N_{\mathrm{e}}$ results should be interpreted with caution if low sample sizes $(<25)$ are analysed. Since rare alleles may highly impact the linkage values, different threshold values were considered $(0.05,0.02$ and 0.01). Evidence of population bottle- 
necks was tested with BOTTLENECK v.1.2.0.2 (Piry et al. 1999) with 95\% stepwise and 5\% multi-step mutations using the two phase mutation model (TPM) that assumes a constant microsatellite mutation rate independent from their repeat lengths. The TPM model was selected as it has been identified as the best alternative for identifying heterozygosity excess in bottleneck analysis (Piry et al. 1999). Statistical significance was determined over 10000 iterations of Wilcoxon's signed statistical tests for heterozygosity excess and heterozygosity deficiency.

\subsubsection{Population differentiation}

To measure levels of genetic admixture between individuals and locations, a hierarchical structure analysis was performed in STRUCTURE v.2.3.4 (Pritchard et al. 2000). Simulations were run using correlated allele frequencies under admixture ancestry models conducting a burn-in of 20000 steps and Markov Chain Monte Carlo (MCMC) iterations of 1000000 reps. The number of genetic clusters $(K)$ varied according to the number of locations tested: (1) 1 to 12 (12 locations considered), (2) 1 to 9 (9 west coast locations) and (3) 1 to 4 (3 east coast locations; here we also included $K=4$ to achieve $\Delta K$ results for both $K=2$ and 3). Each value of $K$ consisted of 10 independent runs. The number of inferred clusters was identified with the Evanno $\Delta K$ method (Evanno et al. 2005) using STRUCTURE HARVESTER (Earl \& vonHoldt 2012) and visualized with the CLUMPAK pipeline (Kopelman et al. 2015). The hierarchical genetic structure was determined by analysis of molecular variance (AMOVA) using 'GenAIEx' v.6.5 under 9999 permutations. Locations were grouped in 3 different regions according to the STRUCTURE results: west coast (FAR, HOG, PAL, HEL, BOR, BJA, LOM, LIM and KUR), SKI and AHU grouped together and KRO as a single group. Genetic differentiation was further evaluated with a population pairwise $F_{\mathrm{ST}}$ matrix, calculated using Arlequin v.3.5.2.2, and a population pairwise $D_{\text {est }}$ (i.e. Jost's $D$ ) using 'GenAIEx' v.6.5. $D_{\text {est }}$ was calculated as a complementary differentiation measure to identify genetic differentiation between subpopulations (Jost 2008). A discriminant analysis of principal components (DAPC) was performed using the 'adegenet' package (Jombart 2008) implemented in R, to identify the membership probability of individuals and to verify spatial genetic structure (combining genetic and geographical data) obtained in STRUCTURE. The analysis was performed in 3 separate approaches: (1) all locations together (100 PCs re- tained), (2) only west coast locations (100 PCs retained) and (3) only east coast locations (15 PCs retained). The function 'find.clusters' was implemented in this package to assess $K$. The program GENECLASS v.2.0 (Piry et al. 2004) was used to estimate short-term migration rates (first-generation migrants). The Rannala \& Mountain (1997) criterion was selected for detecting the likelihood that an individual belongs to the location where it was sampled. Exclusion probabilities from the reference location were calculated using Monte Carlo resampling with 10000 permutations and a threshold probability of 0.01 (Paetkau et al. 2004). A probability over $95 \%$ was required to consider the individual exclusion. Identified migrants were only assigned to another location when there was a probability of over $10 \%$. Magnitude and patterns of gene flow between locations and directional migration based on $D_{\text {est }}$ genetic differentiation were inferred with the function 'DivMigrate' (Sundqvist et al. 2016) in the 'diveRsity' (Keenan et al. 2013) package implemented in R. Statistical significance was evaluated with 10000 bootstraps replications. Isolation by distance (IBD) was tested using a Mantel test where pairwise $F_{\mathrm{ST}}$ and $D_{\text {est }}$ values, respectively, were correlated to sea distances among locations, using the 'mantel.test' function in the 'ncf' package in $\mathrm{R}$ (Bjornstad 2020), where matrices were resampled 100000 times. Sea distances were estimated manually in Google Maps (www.google.com/maps). IBD scatter plots were obtained with the 'ggplot2' package implemented in R (Wickham 2016).

\subsubsection{Environmental association analysis}

To determine independence among all environmental factors, a Spearman correlation was conducted among the 7 factors with the 'Hmisc' package in R (Harrell 2019). An additional Spearman correlation to test independence between the 2 morphological variables was performed under the same package. To determine the influence of environmental factors on morphological variables, a permutational multivariate analysis of variance (PERMANOVA) was performed independently for both leaf width and length, using the 'adonis' function in the 'vegan' package in R (Oksanen et al. 2019) under 9999 permutations. All values were $\log 10$ transformed, and Gower dissimilarities (for non-continuous variables) were considered during the analysis. First, the individual effect of each factor was evaluated through univariate PERMANOVAs, followed by a multivariate analysis including all environmental factors. 
Moreover, a generalized linear model (GLM) was selected to determine the influence of environmental factors on genetic variation $\left(A_{R_{1}} H_{\mathrm{e}}\right.$ and $\left.H_{\mathrm{o}}\right)$ and genotypic variation $(R)$ using the 'MuMIn' (Barton 2019) and 'MASS' (Venables \& Ripley 2002) packages in R. Genetic and genotypic variables were used as dependent variables, and environmental factors as predictors. GLMs for genetic variables used normal error distribution, while a binomial distribution was required for the genotypic variable. All GLMs were assessed for fit through Shapiro-Wilk normality tests and Cook's distance (outliers were removed) in R. First, univariate GLMs testing the influence of each environmental factor were performed. Then, multivariate GLMs - including all 5 predictors - and best fit models were determined. Here, best models (including possible influencing environmental factors) were selected according to Akaike's information criterion $(\mathrm{AIC}$; the best fit model with lowest AIC score) at a p-value $<0.05$. The contribution of each factor to the model was assessed using the Type III likelihood ratio test.

\section{RESULTS}

\subsection{Clonal and genetic diversity}

A total of 205 Zostera marina individuals were collected and genotyped at 10 microsatellite loci. There were 7 to 24 unique MLGs identified per location (Table 2), resulting in 195 genotypically unique individuals that were used for further analysis. Clonal diversity was lower in KRO $(R=0.70)$ compared to all other locations (Table 2). There was no evidence of high frequency of null alleles, as the estimated frequencies were $<10 \%$ (highest for locus ZosmarCT-35 with $4.6 \%$ ), discounting technical issues in the amplification of genomic DNA (Dharmarajan et al. 2013). Significant deviations from HWE $(p<0.05)$ were observed at 10 loci, of which at least 2 loci were significant for every location. These deviations are likely due to heterozygote deficit, as 11 out of 12 locations displayed a significant deficit (44 out of 120 tests [37\%] were significant). Significant LD was identified in 59 out of 540 pairwise interactions across all pairwise locations (11\%) after applying Bonferroni corrections. Locus ZosmarCT-35 and ZosmarCT-17H drove most of the significant deviations for LD and higher null allele frequencies. However, after rerunning genetic diversity and population differentiation analyses on the remaining 8 loci - considering HWE and LD information-results did not show a significant difference in comparison to results with 10 loci. Therefore, 10 loci were kept for further analyses. Statistical power simulations in POWSIM indicated that the 10 microsatellite loci had a $100 \%$ probability of detecting an $F_{\mathrm{ST}}$ as low as 0.0246 , but only a $31 \%$ probability of detecting an $F_{\text {ST }}$ as low as 0.0025 (Table S2).

Overall, levels of genetic diversity of $Z$. marina in Scania were high $\left(A_{R}=3.4, H_{\mathrm{o}}=0.418, H_{\mathrm{e}}=0.467\right)$ and similar among locations. A total of 537 alleles were found across all 12 locations, with a range from 31 to 58 on the west coast and 37 to 39 on the east coast. The number of $P_{A}$ was higher in $\mathrm{KRO}\left(P_{A}=16\right)$ in comparison to all other locations. The mean value of $F_{\text {IS }}$ was $0.196(\mathrm{p}<0.001)$, with a range from 0.038

Table 2. Estimates of clonal and genetic diversity of Zostera marina at 10 microsatellite loci. N: number of sampled ramets; MLG: number of multilocus genotypes; $R$ : clonal diversity; $A_{R}$ : allelic richness (standardized to $7 \mathrm{MLGs)}$ ) $N_{\mathrm{A}}$ : total number of alleles per location; $P_{\mathrm{A}}$ : number of private alleles with frequency $>0.05 ; H_{\mathrm{o}}$ : observed heterozygosity; $H_{\mathrm{e}}$ : expected heterozygosity; $F_{\text {IS }}$ : inbreeding coefficient; ${ }^{*} \mathrm{p}<0.05 ;(-)$ not applicable

\begin{tabular}{|lcccccccccc|}
\hline Location & Code & $\mathrm{N}$ & MLG & $R$ & $A_{R}$ & $N_{\mathrm{A}}$ & $P_{\mathrm{A}}$ & $H_{\mathrm{o}}(\mathrm{SE})$ & $H_{\mathrm{e}}(\mathrm{SE})$ & $F_{\mathrm{IS}}(\mathrm{p})$ \\
\hline Farhult & FAR & 16 & 16 & 1.00 & 3.7 & 46 & 4 & $0.338(0.08)$ & $0.474(0.08)$ & $0.273(<0.01)^{*}$ \\
Höganäs & HOG & 15 & 15 & 1.00 & 3.4 & 46 & 3 & $0.387(0.05)$ & $0.453(0.07)$ & $0.152(0.01)^{*}$ \\
Pålsjö & PAL & 22 & 20 & 0.91 & 3.6 & 51 & 3 & $0.378(0.07)$ & $0.476(0.08)$ & $0.202(<0.01)^{*}$ \\
Helsingborg & HEL & 7 & 7 & 1.00 & 3.1 & 31 & 0 & $0.482(0.06)$ & $0.558(0.08)$ & $0.145(0.081)$ \\
Borstahusen & BOR & 24 & 24 & 1.00 & 3.6 & 53 & 5 & $0.279(0.04)$ & $0.473(0.08)$ & $0.415(<0.01)^{*}$ \\
Bjärred & BJA & 14 & 14 & 1.00 & 3.4 & 42 & 1 & $0.378(0.05)$ & $0.445(0.08)$ & $0.155(0.01)^{*}$ \\
Lomma & LOM & 22 & 22 & 1.00 & 3.8 & 58 & 4 & $0.386(0.04)$ & $0.524(0.07)$ & $0.267(<0.01)^{*}$ \\
Limhamn & LIM & 15 & 15 & 1.00 & 3.5 & 49 & 2 & $0.437(0.06)$ & $0.511(0.07)$ & $0.144(0.02)^{*}$ \\
Kurland & KUR & 23 & 22 & 0.95 & 3.4 & 48 & 3 & $0.395(0.08)$ & $0.428(0.09)$ & $0.077(0.73)$ \\
Skillinge & SKI & 16 & 15 & 0.93 & 3.1 & 37 & 1 & $0.391(0.08)$ & $0.486(0.07)$ & $0.192(0.07)$ \\
Ahus & AHU & 10 & 10 & 1.00 & 3.4 & 37 & 2 & $0.470(0.06)$ & $0.509(0.06)$ & $0.081(0.17)$ \\
Krogstorp & KRO & 21 & 15 & 0.70 & 2.6 & 39 & 16 & $0.455(0.09)$ & $0.474(0.06)$ & $0.038(0.34)$ \\
Total & & 205 & 195 & - & 3.4 & 537 & 44 & $0.418(0.02)$ & $0.467(0.02)$ & $0.196(<0.01)$ \\
\hline
\end{tabular}


in KRO on the east coast to 0.415 in BOR on the west coast (Table 2). Overall, estimates of $N_{\mathrm{e}}$ were generally low on both west and east coasts, with lower values in east coast locations (Table S3). A comparison of results among different threshold values $(p=0.05$, 0.02 and 0.01 ) suggests that the presence of rare alleles could have a large impact on populations (e.g. west coast locations), yet these results do not change the overall result. Results for bottleneck events showed significant evidence of genetic bottlenecks in 5 locations on the west coast (HOG, PAL, BOR, LOM and KUR). However, allele frequencies revealed no influence of recent bottlenecks that could have affected genetic variability, except in one loca- tion on the east coast (AHU). Heterozygote deficiency was present in all locations except KRO (Table S4), which may be related to a historical population expansion.

\subsection{Population differentiation}

$Z$. marina locations showed moderate genetic differentiation despite the recent meadow fragmentation and decline. Bayesian statistical modelling analysis in STRUCTURE identified $K=3$ as the most likely number of clusters (Figs. 2a \& S1). One cluster was present at high frequencies in west coast loca- a
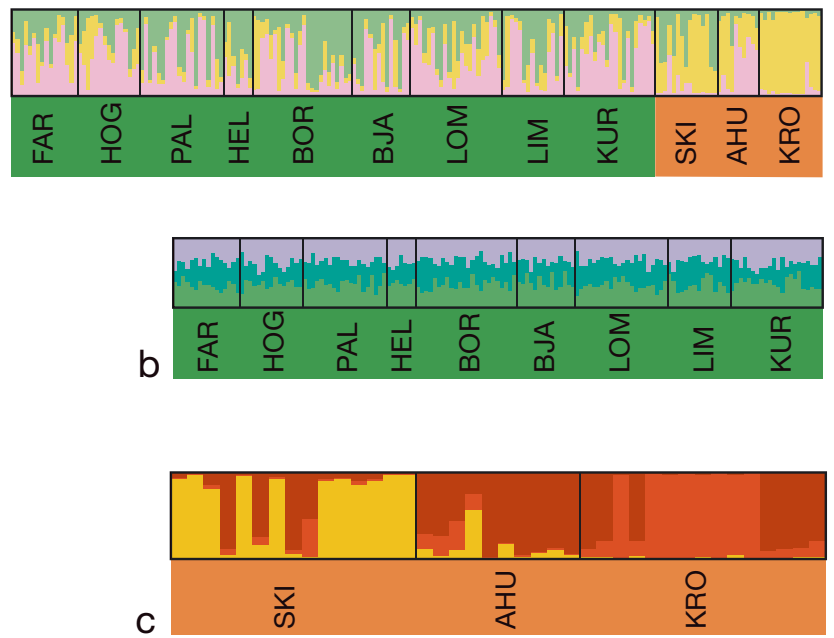
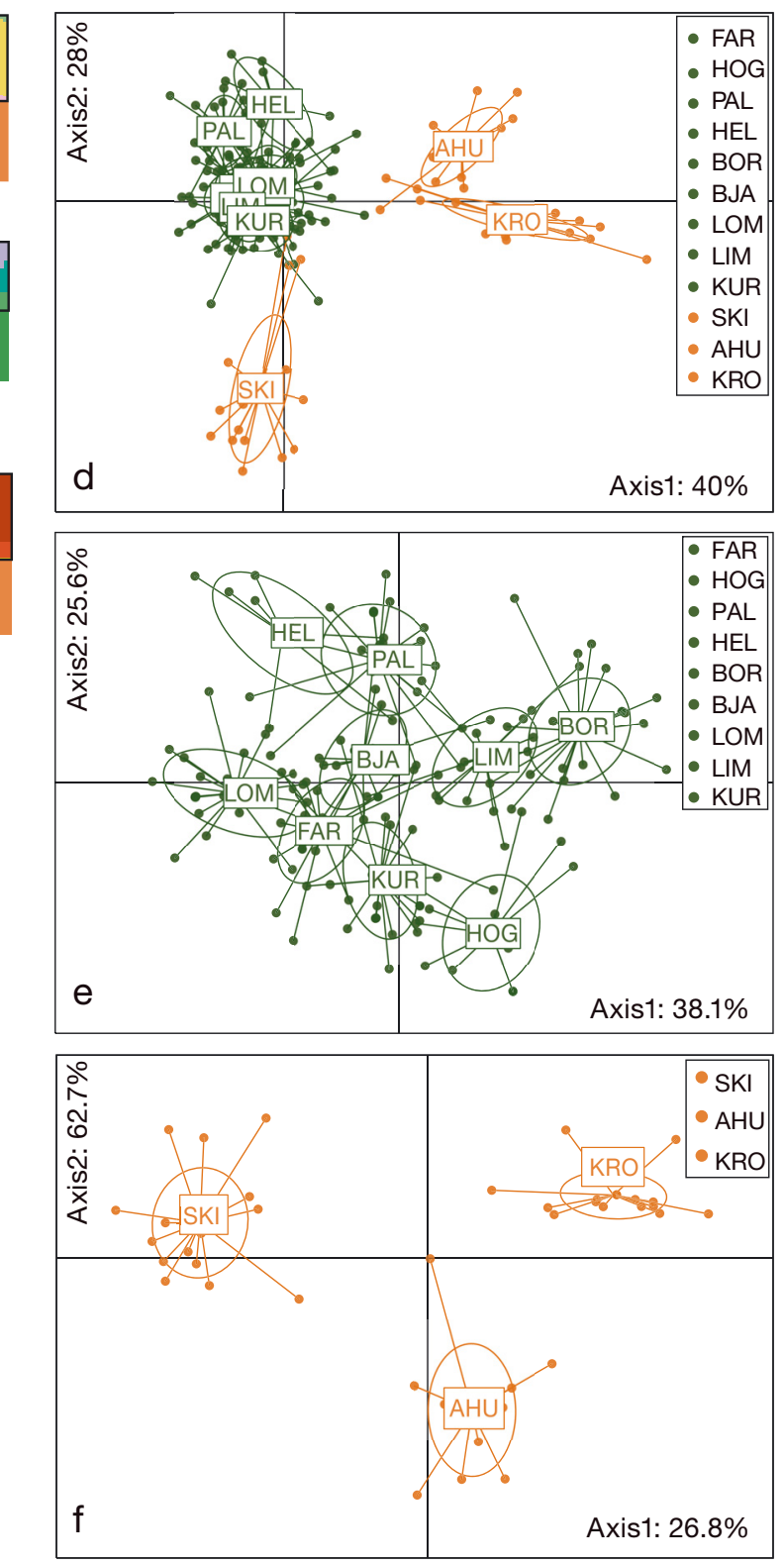

Fig. 2. Spatial population structure performed in STRUCTURE software denoting 3 genetic clusters $(K=3)$ among 12 locations of Zostera marina along the (a) west and east coasts, (b) west coast, and (c) east coast (see Fig. 1 for site abbreviations). Each individual sampled is represented in the $x$-axis, while the $y$-axis denotes the probability of identity to each genetic cluster. Discriminant analysis of principal components denoting (d) 6 genetic clusters $(K=6)$ between west and east coasts, (e) 5 genetic clusters $(K=5)$ within the west coast, and (f) 3 genetic clusters $(K=3)$ within the east coast. Dots: individuals belonging to each location; ellipses: $95 \%$ of the inertia of the corresponding location. Together, the axes explain $68,63.7$ and 89.6 of the variation, respectively 
tions (FAR, HOG, PAL, HEL, BOR, BJA, LOM, LIM and KUR), and 2 clusters were more frequent on the east coast (SKI, AHU and separately KRO). A genetic structure analysis among west coast locations indicated 3 significant genetic clusters $(K=3$; Figs. $2 b$ \& $\mathrm{S} 1)$. Yet no obvious differences were found between locations (Fig. 2b), which suggests a probable single genetic population on the west coast. However, the genetic differentiation between east coast locations was more pronounced and indicated 3 significant genetic clusters ( $K=3$; Figs. 2c \& S1), which separated each location more strongly (Fig. 2c). The hierarchical AMOVA analysis showed $41 \%$ of the variation among groups $(\mathrm{p}<0.001)$, indicating high genetic differentiation among west and east coasts, and within the east coast. Pairwise population differentiation was generally high between coasts, but low within the west coast, when measured with either $F_{\mathrm{ST}}$ (Table 3) or $D_{\text {est }}$ (Table S5). $F_{\mathrm{ST}}$ values ranged from 0.004 to 0.209 , whereas $D_{\text {est }}$ values ranged from 0.000 to 0.358 . Higher levels of differentiation were found between all locations against KRO, for both $F_{\mathrm{ST}}$ and $D_{\text {est }}$ values (Table S5). DAPC analysis revealed 6 genetic clusters among all locations (Fig. 2d), while 5 clusters were found among individuals from west coast locations (Fig. 2e). East coast locations showed genetic distinctiveness between each other (Fig. 2f), with 3 genetic clusters. Membership probabilities in both west and east coasts showed a high association of individuals to their home location, which suggests restricted genetic dispersal. Recent migration rates estimated with GENECLASS identified $12(6 \%)$ out of 195 individuals as first-generation migrants $(\mathrm{p}<$ 0.01; Fig. 3a, Table S6). Results indicate substantial gene dispersal between locations on the west coast with a major dispersal from and towards LOM and
LIM. East coast locations showed restricted dispersal between sites. Gene flow between locations based on 'DivMigrate' analyses revealed a stepping-stone migration pattern. The dispersion was higher among west coast locations compared to the east coast. Two main groups were visible: (1) FAR, HOG, PAL, HEL, BOR and (2) BJA, LOM, LIM, KUR, SKI, AHU, KRO (Fig. 3b), with a moderate restriction between BOR and BJA. However, these dispersion patterns were non-significant. Mantel test results detected a relationship between pairwise $F_{\mathrm{ST}}$ and $D_{\text {est }}$ against sea distances between all locations $\left(F_{\mathrm{ST}}: \mathrm{R}^{2}=0.65, \mathrm{p}=\right.$ 0.003 ; $D_{\text {est }}: \mathrm{R}^{2}=0.59, \mathrm{p}=0.002$ ), which suggests a significant pattern of IBD (Fig. 4).

\subsection{Environmental association analysis}

Spearman correlation analyses indicated that organic matter, sediment and exposure were independent of other factors $(p>0.05)$, whereas salinity and temperature were correlated with each other, as were minimum and maximum depths. Therefore, temperature and minimum depth were removed from further analyses, and the 5 other environmental factors were evaluated. Leaf width and leaf length did not show any significant correlation with each other. Multivariate PERMANOVA analyses with leaf length as the dependent variable of environmental factors only showed a significant interaction with exposure. However, leaf width showed significant relationships with organic matter $(\mathrm{p}<0.001)$, salinity $(\mathrm{p}<0.001)$ and maximum depth $(\mathrm{p}=0.003$; Table S7). Univariate tests showed that almost all environmental factors can significantly influence leaf width, yet no environmental factor displayed any individual

Table 3. Pairwise differentiation index $F_{\mathrm{ST}}$ (below the diagonal) and p-value (above the diagonal) between 12 locations of Zostera marina (see Fig. 1 for site abbreviations). ${ }^{*} p<0.05$

\begin{tabular}{|lcccccccccccc|}
\hline & FAR & HOG & PAL & HEL & BOR & BJA & LOM & LIM & KUR & SKI & AHU & KRO \\
\hline FAR & & 0.009 & 0.021 & 0.027 & 0.001 & 0.046 & 0.011 & 0.044 & 0.654 & 0.000 & 0.011 & 0.000 \\
HOG & $0.039^{*}$ & & 0.083 & 0.003 & 0.082 & 0.281 & 0.149 & 0.005 & 0.189 & 0.000 & 0.000 & 0.000 \\
PAL & $0.029^{*}$ & 0.019 & & 0.011 & 0.017 & 0.869 & 0.129 & 0.095 & 0.094 & 0.000 & 0.000 & 0.000 \\
HEL & $0.053^{*}$ & $0.074^{*}$ & $0.054^{*}$ & & 0.005 & 0.010 & 0.034 & 0.033 & 0.012 & 0.001 & 0.005 & 0.000 \\
BOR & $0.049^{*}$ & 0.023 & $0.028^{*}$ & $0.075^{*}$ & & 0.209 & 0.001 & 0.100 & 0.003 & 0.000 & 0.000 & 0.000 \\
BJA & $0.029^{*}$ & 0.011 & 0.004 & $0.061^{*}$ & 0.017 & & 0.202 & 0.168 & 0.193 & 0.000 & 0.000 & 0.000 \\
LOM & $0.035^{*}$ & 0.016 & 0.014 & $0.046^{*}$ & $0.053^{*}$ & 0.014 & & 0.060 & 0.034 & 0.000 & 0.001 & 0.000 \\
LIM & $0.031^{*}$ & $0.047^{*}$ & 0.019 & $0.057^{*}$ & 0.023 & 0.017 & 0.023 & & 0.013 & 0.000 & 0.000 & 0.000 \\
KUR & 0.004 & 0.010 & 0.013 & $0.046^{*}$ & $0.035^{*}$ & 0.011 & $0.020^{*}$ & $0.034^{*}$ & & 0.000 & 0.000 & 0.000 \\
SKI & $0.098^{*}$ & $0.015^{*}$ & $0.132^{*}$ & $0.119^{*}$ & $0.148^{*}$ & $0.128^{*}$ & $0.094^{*}$ & $0.123^{*}$ & $0.123^{*}$ & & 0.016 & 0.000 \\
AHU & $0.053^{*}$ & $0.103^{*}$ & $0.106^{*}$ & $0.077^{*}$ & $0.134^{*}$ & $0.107^{*}$ & $0.064^{*}$ & $0.103^{*}$ & $0.085^{*}$ & $0.049^{*}$ & \\
KRO & $0.178^{*}$ & $0.197^{*}$ & $0.209^{*}$ & $0.190^{*}$ & $0.178^{*}$ & $0.207^{*}$ & $0.158^{*}$ & $0.172^{*}$ & $0.205^{*}$ & $0.138^{*}$ & $0.093^{*}$ & 0.001 \\
\end{tabular}


a

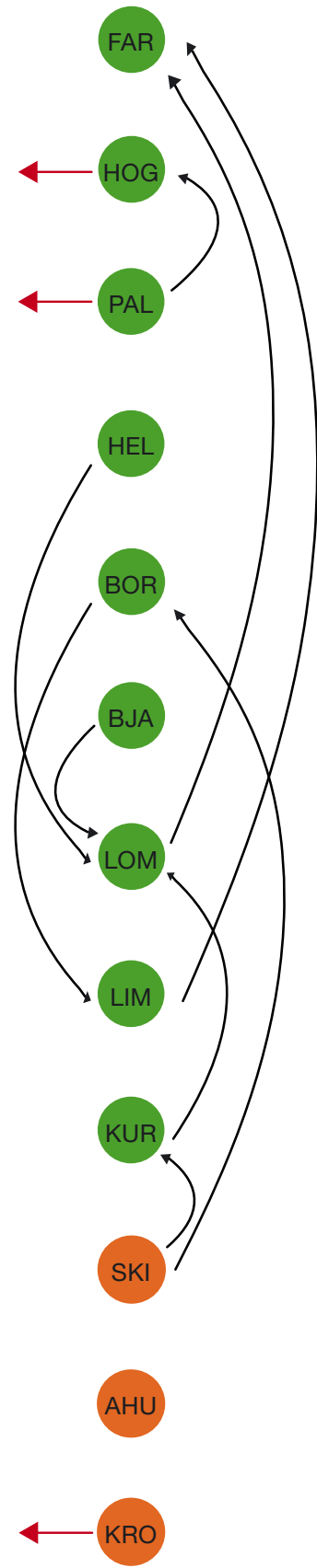

b

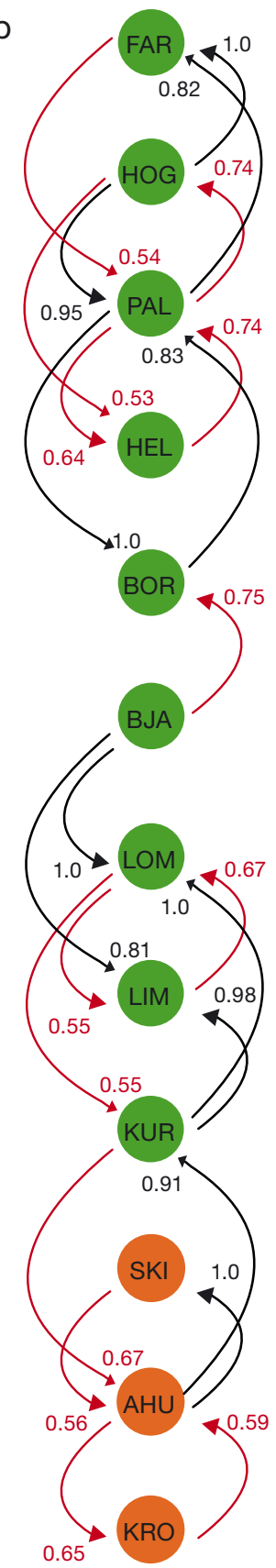

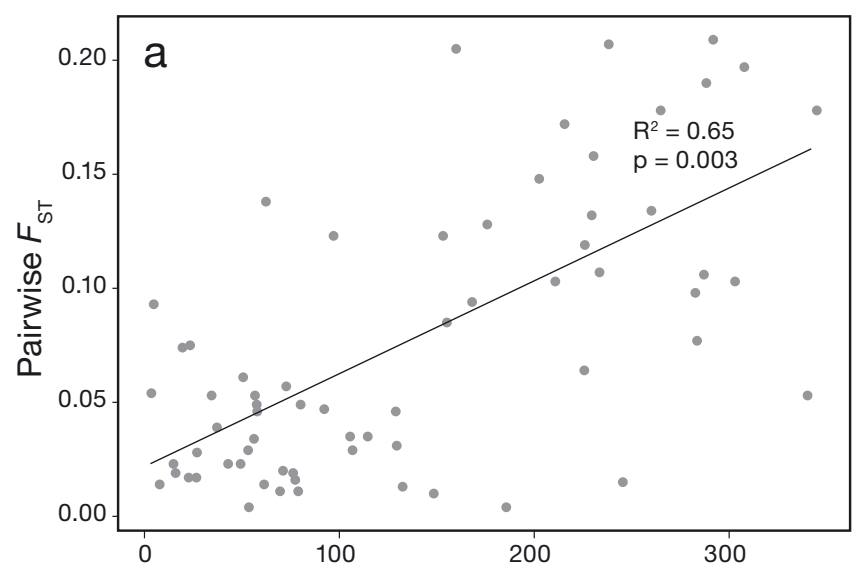

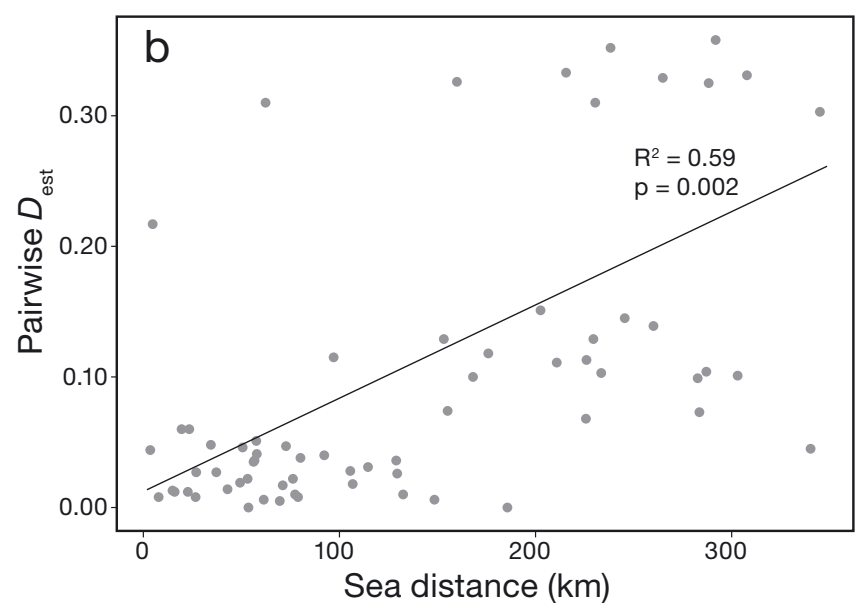

Fig. 4. Mantel test scatter plots representing relationships between sea distance and pairwise differentiation indices (a) $F_{\mathrm{ST}}$ and (b) $D_{\text {est }}$

influence on leaf length. Multivariate GLM analyses between genetic $\left(A_{R}, H_{\mathrm{e}}, H_{\mathrm{o}}\right)$ and genotypic $(R)$ diversities and environmental factors showed a significant and consistent influence of organic matter on $A_{R^{\prime}} H_{\mathrm{e}}$ and $R$, and maximum depth on $H_{\mathrm{e}}, H_{0}$ and $R$ (Table 4). Moreover, salinity only showed a significant influence on $H_{\mathrm{o}}$ and $R$. Sediment and exposure had a weaker influence on the variables in both multivariate and univariate tests.

\section{DISCUSSION} ual with a probability of exclusion of $\geq 95 \%$ from their source location (see Table S6). Red arrows: individuals that were not assigned to any sampled site; black arrows: the migratory patterns among sampled locations. (b) Non-significant relative migration patterns $(\mathrm{p}>0.05)$ based on genetic distance $D_{\text {est }}$ of adjacent locations of $Z$. marina based in relative migration network obtained with 'DivMigrate' analyses. Only migration connections with a threshold above 0.5 are shown; black arrows: connections above 0.8; red arrows: connections below a threshold of 0.79

Fig. 3. (a) Assignment of 12 first-generation migrants of Zostera marina among 12 locations in Scania based on filtered assignment probabilities using GENECLASS (see Fig. 1 for site abbreviations). Each arrow represents an individ- 
Table 4. Results of generalized linear model analyses (GLM) for the contribution of 5 environmental variables (all variables together and individual effect) to explain variation in genetic diversity (allelic richness $\left[A_{R}\right]$, expected heterozygosity $\left[H_{\mathrm{e}}\right]$, observed heterozygosity $\left[H_{0}\right]$ ), genotypic diversity $(R)$, and allele frequencies for Zostera marina at 12 locations. ${ }^{*} \mathrm{p}<0.05$. In the test of all effects, factors that were not selected for best fit model are indicated with ' - '. logOM: logarithm organic matter

\begin{tabular}{|c|c|c|c|c|c|}
\hline $\begin{array}{l}\text { Genetic/ } \\
\text { genotypic } \\
\text { information }\end{array}$ & Test & Best fit model & Factors & $\begin{array}{c}\text { Test } \\
\text { of all } \\
\text { effects } \\
p\end{array}$ & $\begin{array}{c}\text { Test for } \\
\text { individual } \\
\text { effect } \\
\text { p }\end{array}$ \\
\hline$A_{R}$ & GLM & $\log \mathrm{OM}+$ Salinity + Sediment & $\begin{array}{l}\text { Organic matter } \\
\text { Salinity } \\
\text { Sediment } \\
\text { Maximum depth } \\
\text { Exposure }\end{array}$ & $\begin{array}{l}0.002^{*} \\
0.073 \\
0.055 \\
- \\
-\end{array}$ & $\begin{array}{l}0.021^{*} \\
0.003^{*} \\
0.774 \\
0.106 \\
0.600\end{array}$ \\
\hline$H_{\mathrm{e}}$ & GLM & $\log \mathrm{OM}+$ Maximum depth + Exposure + Sediment & $\begin{array}{l}\text { Organic matter } \\
\text { Salinity } \\
\text { Sediment } \\
\text { Maximum depth } \\
\text { Exposure }\end{array}$ & $\begin{array}{l}0.003^{*} \\
- \\
0.841 \\
0.015^{*} \\
0.006^{*}\end{array}$ & $\begin{array}{l}0.198 \\
0.488 \\
0.685 \\
0.001^{*} \\
0.001^{*}\end{array}$ \\
\hline$H_{\mathrm{o}}$ & GLM & $\log \mathrm{OM}+$ Salinity + Sediment + Maximum depth + Exposure & $\begin{array}{l}\text { Organic matter } \\
\text { Salinity } \\
\text { Sediment } \\
\text { Maximum depth } \\
\text { Exposure }\end{array}$ & $\begin{aligned} & 0.462 \\
&< 0.001^{*} \\
&< 0.001^{*} \\
& 0.001^{*} \\
& 0.539\end{aligned}$ & $\begin{array}{l}0.668 \\
0.126 \\
0.960 \\
0.003^{*} \\
0.505\end{array}$ \\
\hline$R$ & GLM & $\log \mathrm{OM}+$ Maximum depth + Salinity & $\begin{array}{l}\text { Organic matter } \\
\text { Salinity } \\
\text { Sediment } \\
\text { Maximum depth } \\
\text { Exposure }\end{array}$ & $\begin{array}{c}<0.001^{*} \\
0.004^{*} \\
- \\
0.026^{*} \\
-\end{array}$ & $\begin{array}{c}<0.001^{*} \\
<0.001^{*} \\
0.520 \\
0.027^{*} \\
0.165\end{array}$ \\
\hline
\end{tabular}

provides information about population structure and dispersal patterns of Zostera marina along the coast of southern-most Sweden (Scania), which is under the unique environmental influence of a distinctive salinity gradient and a wind (wave) exposure that is very different between the western and eastern coastlines.

\subsection{Genetic diversity and population structure}

This study identified similar levels of genetic diversity in Z. marina locations in Scania compared to previous studies of this species in Scandinavia (Olsen et al. 2013, Boström et al. 2014, Jahnke et al. 2018, 2020) and the northern Atlantic waters (Ferber et al. 2008, Alotaibi et al. 2019). High genetic diversity is essential and a prerequisite for long-term management and conservation (Jackson et al. 2021). Seagrass transplantation from highly genotypically diverse meadows into degraded areas could protect against the negative effects of inbreeding and increase the adaptive potential of the meadows (Jackson et al. 2021). For instance, Plaisted et al. (2020) found that $Z$. marina's resilience towards eutrophica- tion was positively correlated with high genetic diversity, and DuBois et al. (2021) identified positive effects of maintaining high genetic and trait diversity across different environmental conditions (differences in temperature and light), highlighting that a dramatic loss of genetic diversity could drive a severe decline of ecosystem functions. On the other hand, in situations where the environment varies locally, directional selection for local environmental conditions may favour specific phenotypes and underlying genotypes, resulting in locally adapted populations (Connolly et al. 2018, Jahnke et al. 2020). In such situations, translocation from distant donor populations may cause maladaptation. Indeed, several environmental factors display strong clines along the coast of Scania, implying that $Z$. marina meadows may differ genetically due to local adaptation. Therefore, successful restoration actions for $Z$. marina need to consider the perspective of preserving the potential for local adaptation together with boosting general levels of variation to avoid genetic depauperation.

The high genetic diversity and high $R$ among $Z$. marina meadows in Scania suggests some degree of sexual reproduction within and among locations. Sexual reproduction with a limitation in mate avail- 
ability may increase the likelihood of inbreeding, which explains the heterozygote deficit (causing deviations from HWE) present across 11 out of 12 locations. Furthermore, high $R$ and inbreeding values in the same location - as shown mostly in west coast locations (Table 2) - suggest close relatedness between distinct genets (Campanella et al. 2010b). Sexual reproduction (and the associated action of recombination that generates [but may also lead to the loss of] new combinations of genetic variants) would accelerate the potential for adaptation to local conditions, which is essential for restoration projects (Jackson et al. 2021). However, microsatellite markers do not directly inform about the adaptive part of the genetic variation (Whitlock 2014).

Of particular interest is the east coast location KRO, where the clonal frequency was lower, and the number of $P_{A}$ was higher (16 out of 39; see Table 2 ) in comparison to all other locations (Table 2). Yet clonal frequency does not seem to be sufficient to impede high genetic diversity. In Z. marina, selected genotypes have been found to cope under highly degraded local conditions, resulting in greater resilience to perturbations (Connolly et al. 2018), which may be suggested for the findings in KRO. Moreover, the high number of $P_{A}$ found in KRO in comparison to other locations could be related to small sample size in a highly genetically diverse population. Here, increasing allele sharing (and thus reduced frequency of $P_{A}$ ) would be observed with an increase in sample size. However, a high prevalence of $P_{A}$ could also be an indicator of the strong effects of genetic drift and small $N_{\mathrm{e}}$ (Johannesson \& André 2006, Jahnke et al. 2018), a situation reflecting elevated risks of extinction.

The $N_{\mathrm{e}}$ among $Z$. marina meadows in Scania (Table S3) are low compared to $N_{\mathrm{e}}$ values found elsewhere (Campanella et al. 2010a, 2013). $N_{\mathrm{e}}$ dissimilarities among meadows and particularly between coasts could be related to the differences in tidal currents, with stronger currents in Öresund (west coast locations), and to the occurrence of recent bottlenecks resulting in population decline and/or recolonization (Procaccini et al. 2007, Olsen et al. 2013); a pattern discovered mainly on the west coast. Such a bottleneck effect scenario follows the findings of de los Santos et al. (2019) for the Baltic Sea.

The recovery of a seagrass meadow not only depends on the genetic variation and reproduction mode but also on the connectivity among these locations (Procaccini et al. 2007). Considering the relatively small geographical scale in this study, we identified a higher genetic structure among $Z$. marina locations compared to previous studies in Scandi- navia and the North Atlantic (Jahnke et al. 2018, Alotaibi et al. 2019). In this study, 3 differentiated genetic clusters among west and east coast locations were found, with few first-generation migrants (12 out of 195 individuals). Jahnke et al. (2018) found a similar result in $Z$. marina meadows within the Skagerrak-Kattegat region, where factors establishing population structure are occasional recruitment (Becheler et al. 2010) and rapid expansion of founding lineages (Waters et al. 2013). These factors may also influence population structuring and dispersal among Z. marina locations in Scania. Infrequent recruitment of only resistant genotypes to disturbed conditions may be present on the east coast, where restricted dispersal was observed (Figs. 2c \& 3b). Moreover, in KRO, low $R$ and restricted dispersal may be indicators of low propagule production (Becheler et al. 2010). Considering only west coast locations, FAR and HEL showed the highest differentiation (Tables $3 \&$ S5). Such high indices for HEL could be related to its proximity to Denmark. In Öresund, Helsingborg (HEL) in Sweden together with Helsingør in Denmark form the narrowest point in the strait; only $4 \mathrm{~km}$ of water separates Zealand (Denmark) and Scania (Sweden), which may favour gene flow between the 2 adjacent coasts, increasing the variation of the gene pool of HEL and making it somewhat different from other locations in the region. Concerning FAR, it is not only the most northern location of our 12 localities but also the only location on the west coast that is outside Öresund and belongs to the Kattegat Sea. Here, occasional migration patterns towards FAR could explain a considerable part of this differentiation; yet possible selection regimes on certain adaptive traits, such as salinity or wave exposure, could be plausible and should be further explored (Johannesson \& André 2006). However, the general weak population structure among west coast locations suggests high admixture, which could be linked to strong dispersal patterns. Water currents, stronger winds and shorter distance among west coast locations facilitates dispersal (Reusch 2002), while the proximity to $Z$. marina meadows in Denmark together with migrating water birds and human vectors (e.g. boats) enable rafting seeds to also migrate long distances (Jahnke et al. 2018). Some of the long-dispersal events and a pattern of IBD in both west and east coast locations (Fig. 3) suggests a stepping-stone dispersal model (Olsen et al. 2004, Jahnke et al. 2018). Special attention needs to be given to key steppingstone dispersal patterns, which are essential not only to maintaining genetic diversity but are crucial to 
keeping connectivity between seagrass meadows and economically important marine species associated with seagrasses (Orth et al. 2020).

\subsection{Environmental effects among populations}

Studies have demonstrated that seagrass populations with high genetic diversity endure under severe conditions and a changing environment, and an adjustment of morphology and physiology-locally adapted to a specific environment - is critical for seagrass survival and optimal growth (Plaisted et al. 2020). The present study identified significant associations between organic matter, maximum depth and salinity with genetic and genotypic variation, as well as with the leaf width of $Z$. marina locations.

The availability of light decreases in deeper living meadows, which negatively influences the growth and survival of $Z$. marina (Krause-Jensen et al. 2011) as significant changes in length and width of leaves have been reported to achieve optimization for photosynthesis and responses to hydrodynamic forces (Eriander et al. 2016, Länsstyrelsen Skåne 2016). Moreover, organic-rich sediments have a negative effect on the anchoring capacity of aquatic plants (Krause-Jensen et al. 2011), which could negatively influence the establishment of recruited seeds as expected in KRO (with 9.99\% organic matter). Lastly, conditions for Z. marina survival, reproduction and growth are optimal at salinity levels around 15 psu, yet Z. marina has a tolerance as low as approximately 5 psu or high as around 30 psu (Nejrup \& Pedersen 2008, Holmer et al. 2009). In this study, salinity levels varied from 5 to 10 psu in the east coast of Scania to 11 to 18 psu between Öresund and Kattegat (Table 1), which could be an explanatory factor for restricted dispersal of $Z$. marina in both the west and east coasts. Salinity levels, particularly on the east coast, may indicate a strong selective force on $Z$. marina meadows in the Baltic Sea. Therefore, careful consideration of these 3 environmental factors for future restoration projects and/or conservation actions is valuable, as resilience to disturbances affecting these particular factors may be conclusive for the survival of a meadow. Further studies, including reciprocal transplants to understand selection and local adaptation in a specific area or whole genome sequencing and identification of single nucleotide polymorphisms (SNPs) to identify signatures of selection in $Z$. marina, are encouraged to understand and predict environmental changes (Jackson et al. 2021).

\subsection{Conservation aspects}

This study focused on the genetic diversity and population structure of $Z$. marina meadows in Scania, Sweden, which offers the possibility to improve and successfully plan restoration projects. For a successful restoration project, it is essential to consider meadows where high $A_{R}, H_{\mathrm{o}}$ and $N_{\mathrm{e}}$ are present as donor populations, along with no evidence of bottlenecks, inbreeding (suggesting the presence of moderate $F_{\mathrm{ST}}$ within meadows) (Campanella et al. 2010a) and significant genetic isolation (Jackson et al. 2021). In this study, no location fulfilled all of these characteristics; nonetheless, BOR, LOM and LIM - and the rest of the locations on the west coast - could potentially act as suitable donor meadows in Scania. These locations are characterized by higher genetic and genotypic diversity and may be key stepping-stone sites that ensure connectivity within the west coast. However, careful considerations are needed regarding environmental similarities - with special attention for organic matter, maximum depth, and salinity - and a potential local adaption factor (Jahnke et al. 2020). Furthermore, all locations on the east coast, in particular KRO, represent geographically disconnected and genetically isolated meadows with small $N_{\mathrm{e}}$. Thus, particular focus and a high priority for the conservation of these 3 locations are suggested with local improvement to promote natural exchange and recolonization (Jackson et al. 2021). Initiatives evaluating $Z$. marina restoration in Swedish territories have been developed (Eriander et al. 2016, Infantes et al. 2016) and, at the moment, there is a large coastal management project 'LIFECOASTadapt', funded by the EU LIFE programme, planning for a number of larger restoration actions at selected locations in Scania (J. Hollander pers. comm.). For that reason, this study is very timely since it offers key information on how to choose suitable donor meadows of $Z$. marina to increase the survival rate of newly founded meadows. Conservation efforts are still an important aspect to implement in order to avoid an unrecoverable loss of the ecosystem and biological diversity. Even though restoration programmes are plausible and an important contribution to seagrass management, they still come with a great economical cost. Therefore, it is important to highlight that it is always more resource-efficient to protect meadows in the first place.

Data availability. The data used for analyses in this work are available in Supplement 2 at www.int-res.com/articles/ suppl/m664p103_supp2.xlsx 
Acknowledgements. The authors thank the editor and 3 anonymous reviewers for encouraging and valuable feedback on the manuscript. The authors also thank Sachin Anand, Mélanie Duc and Amandine Doré for the help given during field collection. This study could not have been possible without the support of Länsstyrelsen Skåne and the projects LIFE17-CCA/SE/000048-LIFECOASTadapt and FORMAS 2018-00640.

\section{LITERATURE CITED}

Alotaibi NM, Kenyon EJ, Cook KJ, Börger L, Bull JC (2019) Low genotypic diversity and long-term ecological decline in a spatially structured seagrass population. Sci Rep 9:18387

Bailleul D, Stoeckel S, Arnaud-Haond S (2016) RClone: a package to identify multilocus clonal lineages and handle clonal data sets in R. Methods Ecol Evol 7: 966-970

Barton K (2019) MuMIn: multi-model inference. R package version 1.43.6. https://CRAN.R-project.org/package=Mu MIn

*Becheler R, Diekmann O, Hily C, Moalic Y, Arnaud-Haond S (2010) The concept of population in clonal organisms: mosaics of temporally colonized patches are forming highly diverse meadows of Zostera marina in Britanny. Mol Ecol 19:2394-2407

Bjornstad ON (2020) ncf: spatial covariance functions. R package version 1.2-9. http://CRAN.R-project.org/ package $=$ ncf

Boström C, Baden S, Bockelmann AC, Dromph K and others (2014) Distribution, structure and function of Nordic eelgrass (Zostera marina) ecosystems: implications for coastal management and conservation. Aquat Conserv 24:410-434

* Campanella JJ, Bologna PA, Smalley JV, Rosenzweig EB, Smith SM (2010a) Population structure of Zostera marina (eelgrass) on the western Atlantic coast is characterized by poor connectivity and inbreeding. J Hered 101: $61-70$

* Campanella JJ, Bologna PA, Smith SM, Rosenzweig EB, Smalley JV (2010b) Zostera marina population genetics in Barnegat Bay, New Jersey, and implications for grass bed restoration. Popul Ecol 52:181-190

* Campanella JJ, Bologna PA, Smalley JV, Avila DNA, Lee KN, Areche EC, Slavin LJ (2013) An analysis of the population genetics of restored Zostera marina plantings in Barnegat Bay, New Jersey. Popul Ecol 55:121-133

* Connolly RM, Smith TM, Maxwell PS, Olds AD, Macreadie PI, Sherman CDH (2018) Highly disturbed populations of seagrass show increased resilience but lower genotypic diversity. Front Plant Sci 9:894

de los Santos CB, Krause-Jensen D, Alcoverro T, Marbà N and others (2019) Recent trend reversal for declining European seagrass meadows. Nat Commun 10:3356

Dharmarajan G, Beatty WS, Rhodes OE Jr (2013) Heterozygote deficiencies caused by a Wahlund effect: dispelling unfounded expectations. J Wildl Manag 77:226-234

* Do C, Waples RS, Peel D, Macbeth GM, Tillett BJ, Ovenden JR (2014) NeEstimator v2: re-implementation of software for the estimation of contemporary effective population size $\left(N_{\mathrm{e}}\right)$ from genetic data. Mol Ecol Resour 14: $209-214$

* Dorken ME, Eckert CG (2001) Severely reduced sexual reproduction in northern populations of a clonal plant, Decodon verticillatus (Lythraceae). J Ecol 89:339-350

* DuBois K, Williams SL, Stachowicz JJ (2021) Experimental warming enhances effects of eelgrass genetic diversity via temperature-induced niche differentiation. Estuaries Coasts 44:545-557

* Earl DA, vonHoldt BM (2012) STRUCTURE HARVESTER: a website and program for visualizing STRUCTURE output and implementing the Evanno method. Conserv Genet 4 : 359-361

Eriander L, Infantes E, Olofsson M, Olsen JL, Moksnes PO (2016) Assessing methods for reforestation of eelgrass (Zostera marina L.) in a cold temperate region. J Exp Mar Biol Ecol 479:76-88

* Evanno G, Regnaut S, Goudet J (2005) Detecting the number of clusters of individuals using the software STRUCTURE: a simulation study. Mol Ecol 14:2611-2620

Excoffier L, Lischer HEL (2010) Arlequin suite ver 3.5: a new series of programs to perform population genetics analyses under Linux and Windows. Mol Ecol Resour 10: $564-567$

F Ferber S, Stam WT, Olsen JL (2008) Genetic diversity and connectivity remain high in eelgrass Zostera marina populations in the Wadden Sea, despite major impacts. Mar Ecol Prog Ser 372:87-96

Goudet J (2002) FSTAT, a program to estimate and test gene diversities and fixation indices (version 2.9.3.2). Institute of Ecology, Lausanne

Harrell FE Jr (2019) Hmisc: Harrell miscellaneous. R package version 4.2-0. https://cran.r-project.org/package= Hmisc

*Holmer M, Bade S, Boström C, Moksnes PO (2009) Regional variation in eelgrass (Zostera marina) morphology, production and stable sulphur isotopic composition along the Baltic Sea and Skagerrak coasts. Aquat Bot 91:303-310

销Infantes E, Eriander L, Moksnes PO (2016) Eelgrass (Zostera marina) restoration on the west coast of Sweden using seeds. Mar Ecol Prog Ser 546:31-45

Jackson EL, Smith TM, York PH, Nielsen J, Irving AD, Sherman CDH (2021) An assessment of the seascape genetic structure and hydrodynamic connectivity for subtropical seagrass restoration. Restor Ecol 29:e13269

Jahnke M, Jonsson PR, Moksnes PO, Loo LO, Nilsson-Jacobi M, Olsen JL (2018) Seascape genetics and biophysical connectivity modelling support conservation of the seagrass Zostera marina in the Skagerrak-Kattegat region of the eastern North Sea. Evol Appl 11:645-661

Jahnke M, Moksnes PO, Olsen JL, Serra Serra N and others (2020) Integrating genetics, biophysical, and demographic insights identifies critical sites for seagrass conservation. Ecol Appl 30:e02121

* Johannesson K, André C (2006) Life on the margin: genetic isolation and diversity loss in a peripheral marine ecosystem, the Baltic Sea. Mol Ecol 15:2013-2029

Jombart T (2008) adegenet: a R package for the multivariate analysis of genetic markers. Bioinformatics 24:1403-1405

Källström B, Nyqvist A, Aberg P, Bodin M, André C (2008) Seed rafting as a dispersal strategy for eelgrass (Zostera marina). Aquat Bot 88:148-153

Jost L (2008) $G_{\mathrm{ST}}$ and its relatives do not measure differentiation. Mol Ecol 17:4015-4026

Keenan K, McGinnity P, Cross TF, Crozier WW, Prodöhl PA (2013) diveRsity: an R package for the estimation of population genetics parameters and their associated errors. Methods Ecol Evol 4:782-788 
Kendrick GA, Orth RJ, Statton J, Hovey R and others (2017) Demographic and genetic connectivity: the role and consequences of reproduction, dispersal and recruitment in seagrasses. Biol Rev Camb Philos Soc 92:921-938

Kopelman NM, Mayzel J, Jakobsson M, Rosenberg NA, Mayrose I (2015) CLUMPAK: a program for identifying clustering modes and packaging population structure inferences across K. Mol Ecol Resour 15:1179-1191

Krause-Jensen D, Carstensen J, Nielsen SL, Dalsgaard T, Christensen PB, Fossing H, Rasmussen MB (2011) Sea bottom characteristics affect depth limits of eelgrass Zostera marina. Mar Ecol Prog Ser 425:91-102

Länsstyrelsen Skåne (2016) Ålgräs i Skåne 2016. Fältinventering och satellitbildstolkning. Länsstyrelsen Skåne, Malmö

Moksnes PO, Eriander L, Infantes E, Holmer M (2018) Local regime shifts prevent natural recovery and restoration of lost eelgrass beds along the Swedish west coast. Estuaries Coasts 41:1712-1731

Nejrup LB, Pedersen MF (2008) Effects of salinity and water temperature on the ecological performance of Zostera marina. Aquat Bot 88:239-246

Oksanen J, Blanchet FG, Friendly M, Kindt R and others (2019) vegan: community ecology package. $R$ package version 2.5-6. https://CRAN.R-project.org/package=vegan

Olsen JL, Stam WT, Coyer JA, Reusch TBH and others (2004) North Atlantic phylogeography and large-scale population differentiation of the seagrass Zostera marina L. Mol Ecol 13:1923-1941

Olsen JL, Coyer JA, Stam WT, Moy FE, Christie H, Jorgensen NM (2013) Eelgrass Zostera marina populations in northern Norwegian fjords are genetically isolated and diverse. Mar Ecol Prog Ser 486:121-132

Orth RJ, Lefcheck JS, McGlathery KS, Aoki L and others (2020) Restoration of seagrass habitat leads to rapid recovery of coastal ecosystem services. Sci Adv 6:eabc6434

* Paetkau D, Slade R, Burden M, Estoup A (2004) Genetic assignment methods for the direct, real-time estimation of migration rate: a simulation-based exploration of accuracy and power. Mol Ecol 13:55-65

Peakall R, Smouse PE (2012) GenAlEx 6.5: genetic analysis in Excel. Population genetic software for teaching and research - an update. Bioinformatics 28:2537-2539

Piry S, Luikart G, Cornuet JM (1999) BOTTLENECK: a computer program for detecting recent reductions in the effective population size using allele frequency data. J Hered 90:502-503

Piry S, Alapetite A, Cornuet JM, Paetkau D, Baudouin L, Estoup A (2004) GENECLASS2: a software for genetic assignment and first-generation migrant detection. J Hered 95:536-539

Plaisted HK, Novak AB, Weigel S, Klein AS, Short DT (2020) Eelgrass genetic diversity influences resilience to stresses associated with eutrophication. Estuaries Coasts 43:1425-1438

* Pritchard JK, Stephens M, Donnelly P (2000) Inference of population structure using multilocus genotype data. Genetics 155:945-959

Editorial responsibility: Adriana Vergés, Sydney, New South Wales, Australia

Reviewed by: C. Sherman and 2 anonymous referees
Procaccini G, Olsen JL, Reusch TBH (2007) Contribution of genetics and genomics to seagrass biology and conservation. J Exp Mar Biol Ecol 350:234-259

R Core Team (2018) R: a language and environment for statistical computing. R Foundation for Statistical Computing, Vienna. www.r-project.org

* Rannala B, Mountain JL (1997) Detecting immigration by using multilocus genotypes. Proc Natl Acad Sci USA 94: 9197-9201

* Reusch TBH (2000) Five microsatellite loci in eelgrass Zostera marina and a test of cross-species amplification in Z. noltii and Z. japonica. Mol Ecol 9:371-373

Keusch TBH (2002) Microsatellites reveal high population connectivity in eelgrass (Zostera marina) in two contrasting coastal areas. Limnol Oceanogr 47:78-85

Reusch TBH, Stam WT, Olsen JL (1999) Microsatellite loci in eelgrass Zostera marina reveal marked polymorphism within and among populations. Mol Ecol 8: 317-321

* Reusch TBH, Stam WT, Olsen JL (2000) A microsatellitebased estimation of clonal diversity and population subdivision in Zostera marina, a marine flowering plant. Mol Ecol 9:127-140

* Rönnbäck P, Kautsky N, Pihl L, Troell M, Soderqvist T, Wennhage H (2007) Ecosystem goods and services from Swedish coastal habitats: identification, valuation, implications of ecosystem shifts. Ambio 36:534-544

Rousset F (2008) GENEPOP '007: a complete re-implementation of the GENEPOP software for Windows and Linux. Mol Ecol Resour 8:103-106

Ryman N, Palm S (2006) POWSIM: a computer program for assessing statistical power when testing for genetic differentiation. Mol Ecol Notes 6:600-602

* Schmidt AL, Wysmyk JKC, Craig SE, Lotze HK (2012) Regional-scale effects of eutrophication on ecosystem structure and services of seagrass beds. Limnol Oceanogr 57:1389-1402

K Sundqvist L, Keenan K, Zackrisson M, Prodöhl P, Kleinhans D (2016) Directional genetic differentiation and relative migration. Ecol Evol 6:3461-3475

Venables WN, Ripley BD (2002) Modern applied statistics, $4^{\text {th }}$ edn. Springer, New York, NY

Wang C, Rosenberg NA (2012) MicroDrop: a program for estimating and correcting for allelic dropout in nonreplicated microsatellite genotypes version 1.01. http:// rosenberglab.stanford.edu/software.html

*Waters JM, Fraser CI, Hewitt GH (2013) Founder takes all: density-dependent processes structure biodiversity. Trends Ecol Evol 28:78-85

*Waycott M, Duarte CM, Carruthers TJB, Orth RJ and others (2009) Accelerating loss of seagrasses across the globe threatens coastal ecosystems. Proc Natl Acad Sci USA 106:12377-12381

Whitlock R (2014) Relationships between adaptive and neutral genetic diversity and ecological structure and functioning: a meta-analysis. J Ecol 102:857-872

Wickham H (2016) ggplot2: elegant graphics for data analysis. Springer-Verlag, New York, NY

Submitted: June 12, 2020

Accepted: February 5, 2021

Proofs received from author(s): April 7, 2021 